\title{
Optimizing of Pneumatic Flexible Joint Skeleton Parameters Based on Orthogonal Experiment
}

\author{
Liu Qi ${ }^{\text {a }}$, Geng Dexu ${ }^{b}$ *, Sun Guodong ${ }^{c}$ \\ School of Mechanica Engineering, Beihua University, Jilin, 132021 \\ aemail:411340633@qq.com, ’email:gengdx64@163.com, cemail:945588276@qq.com \\ ${ }^{*}$ corresponding author
}

Keywords: Flexible Joint; Orthogonal Experiment; Bending Property; Driver

\begin{abstract}
This paper put the flexible joint that can bend to different directions as the research object, and adopted orthogonal experiment to analyze the influence of various parameters on joint bending angle. The experiment results show that the spring diameter of skeleton had the greatest influence on joint bending angle, the effective length is $90 \mathrm{~mm}$, the diameter of $1 \mathrm{~mm}$, the pitch diameter of $7 \mathrm{~mm}$, the pitch of $1 \mathrm{~mm}$, and the flexible joints had best bend performance. The study provides foundation theory and experiment for the application of the flexible joints in the robot drives.
\end{abstract}

\section{Introduction}

With the development of robotics, more and more robots are being applied to medical services and rescue, people also have higher requirements for robot flexibility and compliance [1]. The pneumatic flexible joint has the advantages of flexibility, flexibility and safety, and it has great advantages in the application of robot driver [2-3].Air Muscle [4] produced by British company Shadow and Fluidic Muscle [5-6] produced by German company Festo are mature and have been industrialized. In this paper, the aerodynamic flexible joint is driven by the axial elongated artificial muscle to study the effect of skeleton parameters on its spatial bending performance.

\section{The Structure Composition of Pneumatic Flexible Joint}

The pneumatic flexible joint is composed of the upper end cover, binding ring, skelecton, air bag and the lower cover (Figure 1). The upper end cover and the lower cover is a support of binding ring, skelecton and air bag, and play the role of connecting with external parts. The air bag is made of natural artificial rubber, both ends are mechanically sealed, through the compressed gas. The binding ring material is ABS engineering plastics, can restrain radial deformation of the air bag, and linked the skeleton with the air bag together. The skeleton is a cylindrical spring, increase the stiffness of joint. Different flexible joints differ in the number of air bag and skeletons, and the structure of binding ring and end cover also has differences.

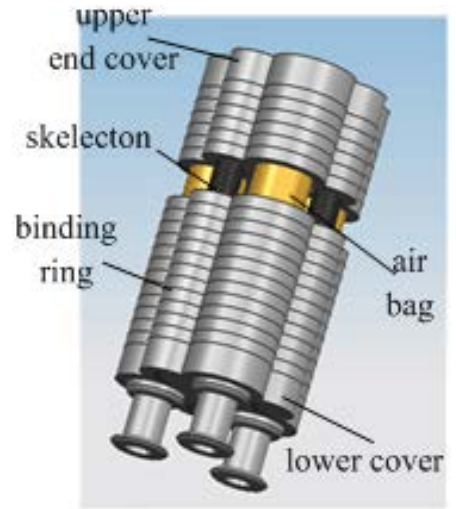

Fig.1 Pneumatic flexible joint structure 
Joints described in this paper was a bend flexible joints in multi-directional space, it has 3 skeletons and 3 air bags. By controlling the pressure value combination of gas into the air bag, the joint can be bent in different directions and angles.

\section{Orthogonal Experiment Design}

The size of space bending Angle is an important index to measure the performance of pneumatic flexible joints. The orthogonal experiment is designed to determine the influence of the parameters of the skeleton spring on the joint space bending Angle.

In this experiment, the parameters of spring that influence the joint space bending Angle is effective length, diameter, pitch diameter, pitch. Three different variables were selected for each parameters, so the experiment included 4 levels and 3 factors. According to experimental requirements select orthogonal table L9(34), orthogonal experimental factor-level table is shown in Table 1.

Table 1 Orthogonal experimental factors - level table

\begin{tabular}{ccccc}
\hline factors & $\begin{array}{c}\text { A } \\
\text { length } \\
\text { level }\end{array}$ & $\begin{array}{c}\text { B } \\
\text { diameter } /\end{array}$ & $\begin{array}{c}\text { C } \\
\text { Pitch }\end{array}$ & D \\
& mm & iametch $/ \mathrm{mm}$ & \\
\hline 1 & 90 & 0.6 & 5 & 0 \\
2 & 120 & 0.8 & 6 & 0.5 \\
3 & 150 & 1 & 7 & 1 \\
\hline
\end{tabular}

\section{Experiment and Analysis of Space Bending Angle}

The experimental principle is shown in Figure 2. The bottom of the joint is fixed on the experimental table, air pressure control system is used to adjust the air pressure in the air bag, the top of the joint will bend in different directions when the air pressure inside the three air bags is different. The gyro and magnetic compass collected data changes in their bending Angle and direction, and uploaded them to the computer. By analyzing the change of bending Angle and direction of flexible joint, we can know its performance.

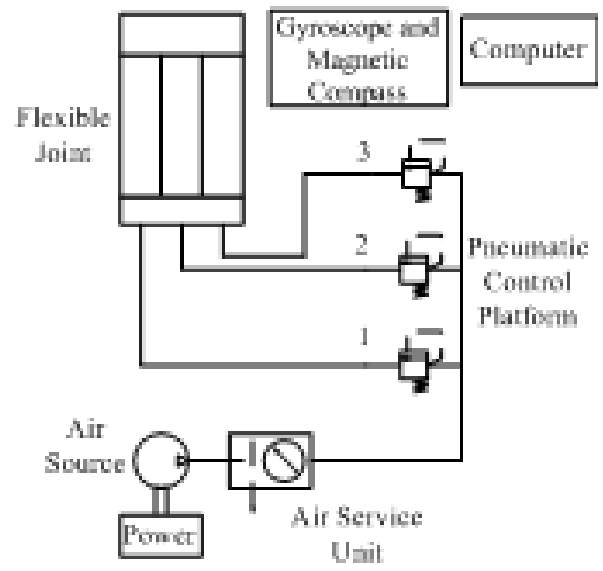

Fig.2 Experimental principle of space bending Angle

The experimental device is composed of air source, pneumatic control platform, a gyroscope, magnetic compass and an upper computer (Figure 3). According to the principle of experiment, fix the joint vertically on the test stand, studied the bending performance of joint when it was drivered by 2 artificial muscle. When the artificial muscles of No. 2 and No. 3 are introduced into the same air pressure, the joint is bent in the negative direction of the Y-axis(Figure 4), and the bending angle is large, Through experiments, the bending angle of joints under different air pressures was obtained, 
and the experimental data were orthogonally processed (Table 2).

The meanings and calculations of the parameters in Table 2 are as follows:

(1) $\theta_{j i}, j=1,2,3,4 ; i=1,2,3$; represents the sum of the values of the $i$-th horizontal joint bending angle under the $\mathrm{j}$-th factor.

(2) $\bar{\theta}_{j i}, j=1,2,3,4 ; i=1,2,3$; represents the arithmetic mean of the value of the $i$-th horizontal joint bending angle under the $j$-th factor.

(3) $R_{1 j}, j=1,2,3,4$, which means that the maximum value of $\theta_{j i}$ minus the minimum value of $\theta_{j i}$ in the three horizontal joints under factor $\mathrm{j}$ is extremely poor.

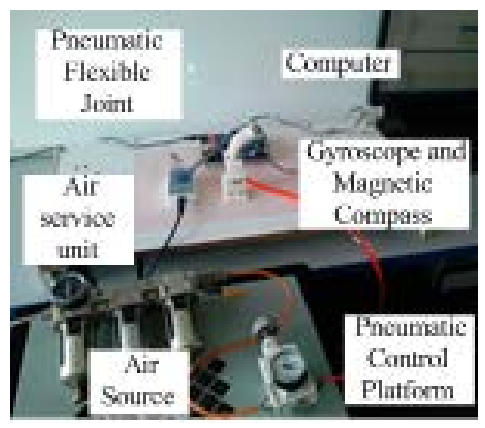

Fig.3 experimental device

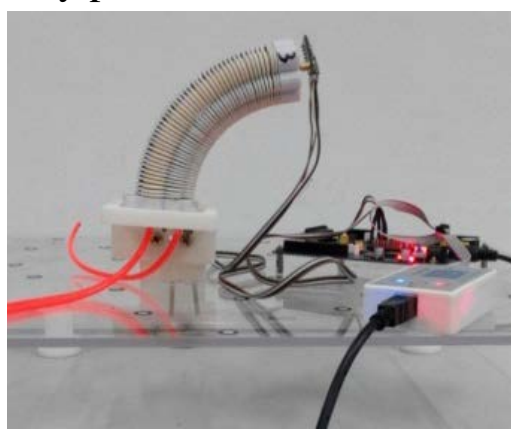

Fig. 4 double drive joint deformation

Table 2 Bending Angle Orthogonal Test Data Sheet (Dual Drive)

\begin{tabular}{|c|c|c|c|c|c|}
\hline $\begin{array}{l}\text { Joint } \\
\text { number }\end{array}$ & $\begin{array}{c}\text { A } \\
\text { length } \\
(\mathrm{mm})\end{array}$ & \begin{tabular}{l}
\multicolumn{1}{c}{ B } \\
Spring \\
diameter \\
$(\mathrm{mm})$
\end{tabular} & $\begin{array}{c}\text { C } \\
\text { Spring } \\
\text { diameter } \\
(\mathrm{mm})\end{array}$ & $\begin{array}{l}\text { D } \\
\text { Spring } \\
\text { pitch } \\
(\mathrm{mm})\end{array}$ & $\begin{array}{c}\text { Bending } \\
\text { angle (") } \\
\theta_{i}\end{array}$ \\
\hline 1 & 90 & 0.6 & 5 & 0 & 118.3 \\
\hline 2 & 90 & 0.8 & 6 & 0.5 & 92.3 \\
\hline 3 & 90 & 1 & 7 & 1 & 57.7 \\
\hline 4 & 120 & 0.6 & 6 & 1 & 157.5 \\
\hline 5 & 120 & 0.8 & 7 & 0 & 148.9 \\
\hline 6 & 120 & 1 & 5 & 0.5 & 45.4 \\
\hline 7 & 150 & 0.6 & 7 & 0.5 & 188.1 \\
\hline 8 & 150 & 0.8 & 5 & 1 & 73.9 \\
\hline 9 & 150 & 1 & 6 & 0 & 126.1 \\
\hline$\theta_{j 1}$ & 268.300 & 463.900 & 237.600 & 393.300 & \\
\hline$\theta_{j 2}$ & 351.800 & 315.100 & 375.900 & 325.800 & \\
\hline$\theta_{\beta}$ & 388.100 & 229.200 & 394.700 & 289.100 & \\
\hline$\overline{\theta_{f t}}$ & 89.433 & 154.633 & 79.200 & 131.100 & \\
\hline$\overline{\theta_{j 2}}$ & 117.267 & 105.033 & 125.300 & 108.600 & \\
\hline$\overline{\theta_{j^{3}}}$ & 129.367 & 76.400 & 131.567 & 96.367 & \\
\hline$R 1$ & 39.933 & 78.233 & 52.367 & 34.733 & \\
\hline $\begin{array}{l}\text { Excellent } \\
\text { level } \\
\text { Primary }\end{array}$ & A3 & $\mathrm{B} 1$ & $\mathrm{C} 3$ & D1 & \\
\hline $\begin{array}{l}\text { and secondary } \\
\text { factors }\end{array}$ & & \multicolumn{2}{|c|}{$B C A D$} & & \\
\hline $\begin{array}{l}\text { Optimal } \\
\text { combination }\end{array}$ & & \multicolumn{2}{|c|}{$\mathrm{A} 3 \mathrm{~B} 1 \mathrm{C} 3 \mathrm{D} 1$} & & \\
\hline
\end{tabular}


The primary and secondary factors are selected according to the Range size. The largest is the main factor, while the smallest is the secondary factor. The order of primary and secondary factors is determined according to the Range size.

As shown in Figure 5, Figure 6 and Figure 7, the Angle changes of each joint under different pressure. It can be seen that the bending Angle of the joint increases with the increase of pressure value and shows a certain non-linearity.

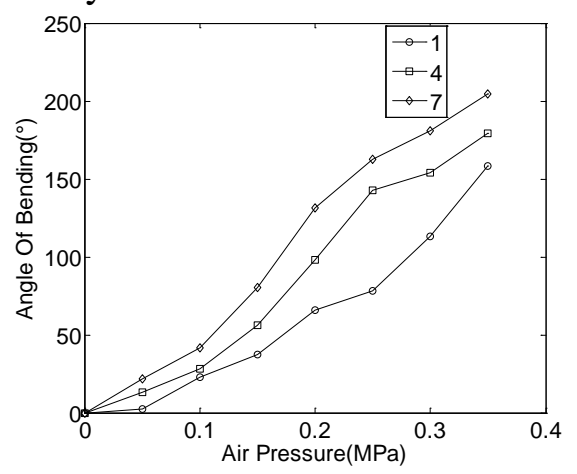

Fig.5 Curves of joint pressure and bending angle of group A

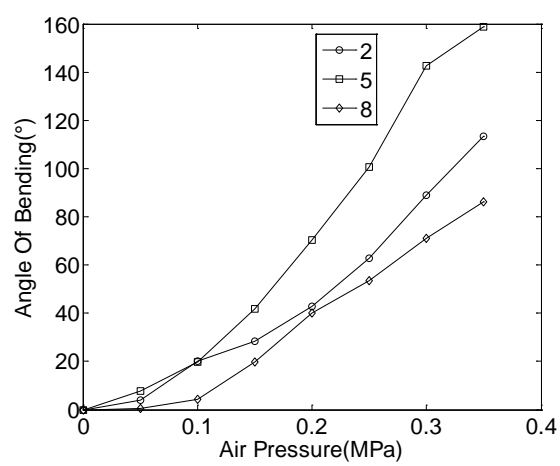

Fig.6 Curves of joint pressure and bending angle of group B

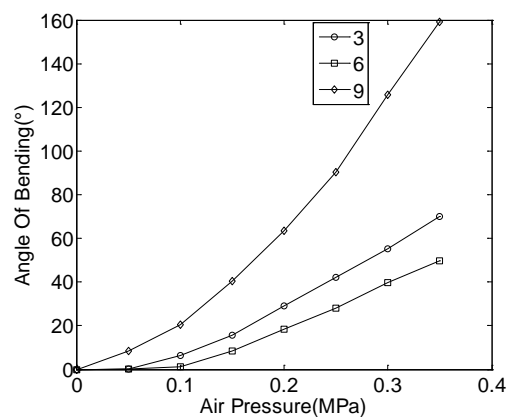

Fig.7 Curves of joint pressure and bending angle of group C

\section{Conclusion}

In this paper, the parameters of skeleton spring which affect the bending angle of joints are experimentally analyzed by orthogonal test. The experimental results show that the spring diameter has the greatest influence on the joint bending angle, and the other factors are spring middle diameter, spring effective length and spring pitch in turn. When the effective length of skeleton spring is $90 \mathrm{~mm}$, diameter is $1 \mathrm{~mm}$, diameter is $7 \mathrm{~mm}$, pitch is $1 \mathrm{~mm}$, the joint bending angle is 57.7 degrees, and the performance of flexible joint is the best. This study provides theoretical and experimental conditions for the selection of the skeleton parameters of pneumatic flexible joints, and lays a foundation for the application of flexible joints in robot actuators. 


\section{Acknowledgements}

The project is supported by Key Science \& Technology Brainstorm Project of Jilin Provincial Science \& Technology Department (20180201050GX) and Graduate student innovation program of Beihua University (201418290).

\section{References}

[1] Guan Qinghua. Research a smart flexible bending pneumatic artificial muscle [D]. Harbin Institute of Technology, 2017.

[2] Zhao Yunwei,Geng Dexu, Liu Xiaomin, et al. Experimental study on dynamic properties of pneumatic space bending Joint [J]. Machine Tool \& Hydraulics, 2017, 45 (23): 10-13.

[3] Zhang Jintao,Geng Dexu,Liu Xiaomin,et al. Mechancal characteristics analysis of two-way active bending flexible pneumatic joint [J]. Hydraulic and pneumatic, 2011(06):39-42.

[4] Tuffield P, Elias H. The Shadow Robot Mimics Human Actions [J]. Industrial Robot: An International Journal, 2003, 30(1):56-60.

[5] Hesse S. The fluidic muscle in application [M].Festo AG \& Company, 2003 